\title{
A CONSTRUÇÃO DE CONCEITOS EM BOTÂNICA A PARTIR DE UMA SEQUÊNCIA DIDÁTICA INTERATIVA: proposiçōes para o ensino de Ciências
}

\author{
Renato Araújo Torres de Melo Moul53 \\ Flávia Carolina Lins da Silva 54
}

\section{RESUMO}

A botânica, uma das áreas de estudo da Biologia, é vista por muitos docentes como um obstáculo para a transposição didática. $O$ ensino de botânica por vezes se dá de forma desarticulada e desprovido de contextualização, numa abordagem que dificulta a adequada aprendizagem dos conceitos. A fim de compreender a construção dos conceitos científicos de vinte e quatro estudantes do Ensino Médio acerca de temas em botânica, empregamos a Sequência Didática Interativa (SDI), com o acompanhamento da elaboração do conhecimento por etapas e em interação com os pares. Como resultado, observou-se que muitas concepções dos estudantes são reafirmadas após a sequência didática, novos conceitos aparecem na formulação de argumentos e ainda, se produz uma visão holística, articulando as plantas entre os diversos níveis de organização em Biologia.

Palavras-chave: Ensino. Conceitos. Botânica.

\section{THE CONSTRUCTION OF BOTANICAL CONCEPTS FROM AN INTERACTIVE DIDACTIC SEQUENCE: propositions for the teaching of Sciences}

\begin{abstract}
Botany, one of the study areas of biology, is seen by many teachers as an obstacle to didactic transposition. The teaching of botany sometimes occurs in a fragmented way and without contextualization, in an approach that hinders the proper learning of concepts. In order to understand the construction of the scientific concepts of twenty-four high school students about botany subjects, we used the Sequência Didática Interativa (SDI), with the follow-up of the elaboration of knowledge in steps and in interaction between students. As a result, it was observed that many conceptions of students are reaffirmed after the didactic sequence, new concepts appear in the formulation of arguments and a holistic view is produced, articulating the plants with the different levels of organization in Biology.
\end{abstract}

Keywords: Teaching. Concepts. Botany.

53 Mestrando do Programa de Pós-Graduação em Ensino de Ciências pela Universidade Federal Rural de Pernambuco (UFRPE). E-mail: torresmoul@gmail.com.

54 Doutorado em Biologia Vegetal pela Universidade Federal de Pernambuco. Professora Associada da Universidade Federal Rural de Pernambuco. Área de Ensino das Ciências Biológicas. Departamento de Biologia. E-mail: flaviaclds@gmail.com /flavia.lins@ufrpe.br 


\section{LA CONSTRUCCIÓN DE CONCEPTOS EN BOTÁNICA DESDE UNA SECUENCIA DE \\ ENSEÑANZA INTERACTIVA: propuestas para la enseñanza de las ciencias}

\section{RESUMEN}

La botánica, una de las áreas de estudio de biología, es vista por muchos profesores como un obstáculo para la transposición didáctica. La enseñanza de la botánica a veces ocurre de forma inconexa y fuera de contexto, con un enfoque que dificulta el correcto aprendizaje de conceptos. Con el fin de comprender la construcción de los conceptos científicos de veinticuatro estudiantes de secundaria sobre temas de botánica, se utilizó una secuencia de enseñanza interactiva con el seguimiento de la evolución de los conocimientos en etapas y la interacción con sus compañeros. Como resultado, se observó que muchas concepciones de los estudiantes se reafirman después de la secuencia de enseñanza, nuevos conceptos aparecen en la formulación de alegaciones, así como una visión integral, articulando las plantas entre los diversos niveles de organización en Biología.

Palabras clave: Enseñanza. Conceptos. Botánica.

\section{INTRODUÇÃO}

As situações de ensino e aprendizagem devem promover a construção do conhecimento no percurso acadêmico de cada estudante. Todavia, por vezes, após uma série de exposições do conteúdo e consequente execução de atividades - que nada mais permitem que simples reproduções - o produto gerado não viabiliza a correta assimilação dos conceitos e sua aplicação em situações de vivências distintas, por parte do discente.

Diversas áreas de ensino da Biologia, uma ciência natural que lida com um objeto de estudo que ora se mostra abstrato ora se mostra concreto, apontam dificuldades aos docentes que ministram suas aulas com métodos engessados que não viabilizam a construção do conhecimento, numa "abordagem do currículo que ocorre desprovida de considerações históricas e pautada na simples apresentação de nomes científicos, com um complexo conjunto de conceitos e sistemas de classificações não apreendidos pelos educandos (MORALES, 2014)". Para muitos docentes, uma contextualização não se opera e o processo de ensino-aprendizagem 
"revela-se como o estudo de nomenclaturas técnicas utilizando-se de metodologias tradicionalistas que estimulam a memorização dos conteúdos" (ARAÚJO; SILVA, 2015).

O contexto atual do Ensino de Ciências, exige um olhar amplo, não apenas focado no próprio objeto de estudo, como pregava o reducionismo e o estudo das partes desarticuladas. Morais (2007) nos relembra que estamos vivendo um novo modelo de vida e de universo, estamos vivendo uma nova episteme que é dotada de múltiplas faces.

Com relação aos estudantes, o docente deve considerá-los, como aponta Behrens (2013), seres originais, únicos e indivisos, um ser de relações, contextualizado e dotado de múltiplas inteligências. Sendo, por isso, importante promover projetos criativos e transformadores em sala de aula, que ultrapassem o ensino mecânico e provoquem uma aprendizagem que gera significados.

Com relação aos conteúdos, deve-se romper com uma postura puramente cartesiana, cujo olhar se mostra fragmentado e estanque. Com o avanço do conhecmento científico, as fronteiras das disciplinas se alargaram, mas ao mesmo tempo, se aproximaram. Cabe ao professor mais uma vez, sensibilidade para transitar - em sua prática pedagógica - entre os limites conceituais com fluidez.

Neste sentido, Keller (2005) sugere uma profunda mudança na compreensão dos seres vivos, propondo que mudemos o foco das entidades ou componentes dos sistemas vivos - vistos isoladamente - para os seus processos de interação em redes bastante complexas. De acordo com a autora, isto deverá ser uma importante mudança, em termos teóricos e metodológicos, pois permitirá não só a assimilação da estrutura e função das partes constituintes dos sistemas biológicos, como também compreender como essas partes estão conectadas entre si, como elas operam mutuamente, como elas interagem em níveis de organização com diversos graus de complexidade e, além disso, aninhados entre si. 


\section{O ENSINO DE BOTÂNICA}

Colênquima, parênquima, esporófito, gametófito, androceu, endocarpo, megásporo, rizoma, coifa. Termos e termos cujo glossário se mostraria interminável. Em muitos casos, palavras como estas são "metralhadas" nas exposições do conteúdo, sem produzir nenhum significado aos ouvintes, mas sim, embaraços e mais incompreensões. Por este motivo, Salatino e Buckeridge (2016) afirmam que na época do Brasil colonial citar termos de botânica era elegante. Todavia, ressalvam os autores, atualmente a referida matéria é concebida pelos estudantes como árida e fora do contexto moderno; e até no meio acadêmico o termo Biologia Vegetal é mais bem quisto entre alguns autores.

A Botânica também é vista como obstáculo, por muitos professores, para a transposição didática. Ceccantini (2006) afirma que muitos professores de Biologia fogem das aulas de Botânica alegando ter dificuldade em desenvolver atividades práticas que despertem curiosidade nos estudantes e mostrem a utilidade daquele conhecimento no seu dia-adia. Uno (2009) indica que os estudantes não veem plantas ou botânica como um conteúdo inerentemente interessante, sendo as temáticas sobre animais e humanos os principais motivos de interesse para aqueles que seguem carreira na Biologia. Amadeu e Maciel (2014) apontam que as experiências de ensino dos conteúdos botânicos são consideradas desinteressantes por parte dos educandos, uma vez que as práticas pedagógicas empregadas geram um aprendizado mecânico e com baixo rendimento escolar.

Este é um problema que se repete nos ambientes de ensino: os estudantes não aprendem e suas "notas baixas" revelam apenas o desinteresse destes para com o conteúdo. Por outro lado, esses dados geram inquietações que nos trazem indagações, a ponto de levar-nos a uma reflexão da prática pedagógica, a fim de saber se essa problemática se relaciona apenas ao desinteresse dos estudantes. A forma como se 
aborda um conteúdo e como se operacionaliza o ensino e a aprendizagem não seriam também influenciadoras destes resultados em sala de aula?

Silva, Cavallet e Alquini (2006) afirmam que mesmo com uma fundamentação pedagógica crítica, é possível, que alguns professores considerem muito mais prático e cômodo conduzir o aprendizado dos conteúdos de Botânica "pensando" apenas em quais diferentes recursos didáticos utilizar dentro de uma lógica formal, do que refletir criticamente sobre o caráter inerentemente relacional do conteúdo, ou seja, na perspectiva do contexto social, econômico, histórico, cultural, ambiental.

Outrossim, essas reflexões por si só não geram a necessária renovação do ensino, sem que antes haja um compromisso maior com o olhar do docente para o discente que lhe rodeia, pois como se vê:

É muito comum acontecer de os alunos passarem de uma série para outra e em pouco tempo esquecerem grande parte do conteúdo específico que o professor considerou relevante. O que mais importa é que os alunos apreendam os conhecimentos necessários de forma articulada porque assim fará muito mais sentido para eles. Além disso, é importante também que eles apreendam os caminhos que devem percorrer caso necessitem aprofundar os assuntos em outra ocasião. A autonomia intelectual só é construída quando o aluno constrói os mecanismos necessários para tal fim e essa é a maior aprendizagem que um professor pode proporcionar (SILVA, CAVALLET e ALQUINI, 2006).

O professor deve promover a ação de reflexão, de construção pensada dos conceitos. Não se ater apenas às exposições orais do conteúdo. Deve sobretudo, permitir aos discentes que participem desta construção, principalmente em Biologia, uma ciência com vasta riqueza de terminologias. Terminologias estas que devem ser utilizadas como ponte e não como muros no processo de ensino e aprendizagem.

As palavras possuem esse potencial de ação para a sensibilidade, para o pensamento, porque:

Algumas palavras, antes que se desgastem ou se fossilizem para nós, antes de permanecerem capturadas pelas normas do saber e pela disciplina do pensar, antes que as convertamos em parte de uma doutrina ou de uma metodologia, antes que nos subordinem, ainda 
podem conter um gesto de rebeldia, um não, podem ser perguntas, aberturas, inícios, janelas abertas, modos de continuar vivos, de prosseguir, caminhos de vida, possibilidades do que não se sabe, talvez (LARROSA, 2016, P. 75).

Bocki et al, (2011) ressaltam que a problemática do ensino de Botânica não se resume apenas à sala de aula, mas que mesmo nos documentos que regem o ensino - como os Parâmetros Curriculares Nacionais (BRASIL, 1998) e as Orientações Curriculares para o Ensino Médio (BRASIL, 2008) -, não há um enfoque direcionado para estudo da Botânica, que aparece como figurante num cenário que tem como protagonista a biodiversidade. Evidenciando-se assim, o que alguns pesquisadores denominam "cegueira botânica" (MENEZES et al, 2009; TOWATA, URSI e SANTOS, 2010). Wandersee e Schussler (1999) cunharam a frase "plant blindness" para caracterizar a inabilidade para ver as plantas em seu próprio ambiente, levando à inabilidade de reconhecer a importância das plantas na biosfera.

Felizmente, é possível usar concepções alternativas de estudantes para mapear o ensino, detectando deficiências e lacunas, que com a consequente intervenção didática, poderá reorientar as práticas pedagógicas e contribuir para um processo de ensino e aprendizagem bem sucedido. Hershey (2004, 2005) tem escrito extensivamente sobre concepções equivocadas em botânica, classificadas em simplificações, generalizações e conceitos obsoletos. Entre elas, figuram com maior frequência a ideia de glicose como maior produto da fotossíntese e a visão de plantas como sendo organismos exclusivamente terrestres. Muitas destas concepções são por vezes disseminadas pelos livros didáticos, um recurso usado extensivamente nas salas de aula.

Diversas pesquisas apontam concepções inadequadas acerca das plantas, por parte das crianças e até mesmo dos adultos, após sua formação básica. McNair e Stein (2001) mostram que ao pedir para crianças e adultos desenharem uma planta, eles frequentemente desenham apenas as flores. Bell (1981) mostrava que alguns estudantes do ensino básico não 
consideravam árvores como plantas e só consideravam um organismo como planta se ao menos possuísse flores.

Uma forma de romper as obstruções no ensino de Botânica está, segundo Bonfim et al, (2015), na compreensão do papel mediador do professor entre os educandos e seus conhecimentos prévios, associados às práticas que valorizem os saberes locais estimulando a participação de todos na conservação da biodiversidade. Ainda segundo os autores, os educadores em suas práticas pedagógicas, além do conhecimento científico, devem valorizar os saberes que os educandos já possuem sobre plantas, pois o uso destas faz parte do dia a dia das comunidades em que estão inseridos. Evidencia-se a necessidade de atividades educativas que tornem a escola um ambiente propício para a produção científica, partindo das representações simbólicas construídas historicamente pelos alunos. Ausubel (1978) já afirmava que o processo de aprendizagem depende do conhecimento que o estudante já possui, o seu conhecimento prévio, pois o fator mais importante influenciador da aprendizagem é o que o aluno já sabe.

Em alguns trabalhos, levantamentos do conhecimento prévio dos estudantes acerca de plantas revelaram dados que elucidam alguns questionamentos relacionados à aprendizagem em Botânica, trazendo em geral, definições de plantas vagas e generalistas que apresentam conceitos incompletos ou em nível muito básico por parte dos discentes (BRITO, 2009; BOCKI et al, 2011 ; SILVA; GHILARD-LOPES, 2014). Para identificar concepções equivocadas dos estudantes, Uno (2009) sugere construir uma base de dados com questões que os estudantes esquecem de responder nos exames e os tipos de repostas que eles dão.

(1) Essas experiências diárias contribuem para a consolidação dos modos de pensar, haja vista que, segundo Bloor (2009), na sociedade se mantem padrões coletivos de pensamento na psique individual, aproximando este conhecimento da cultura. As interações entre os estudantes, dos estudantes para com o professor, e ainda para com os 
recursos didáticos, promovem o pensamento conceitual que, segundo Mortimer e El-Hani (2013), é um processo produzido por meio da interação entre um indivíduo e alguma experiência externa, assumindo sempre uma dimensão social e não inteiramente interna ao sujeito. No que se refere à sala de aula, Santos (2005) aponta que ao se estabelecer uma relação de reflexão mais sistematizada com um determinado assunto, o estudante alcança condições de selecionar algumas ideias e criar conexões entre elas, construindo assim modelos científicos sobre determinado tema.

Neste contexto, dadas as inquietações emergidas, surge a seguinte questão de pesquisa: como os estudantes constroem os conceitos em Botânica, mais especificamente o conceito de planta, a partir de uma sequência didática que possibilite diversos estímulos e recursos didáticos?

\section{CAMINHO METODOLÓGICO}

Este trabalho possui uma natureza qualitativa descritiva, "vista com uma maneira de dar poder ou dar voz às pessoas, em vez de tratá-las como objetos, cujo comportamento dever ser quantificado e estatisticamente modelado" (BAUER et al. 2002, p. 30). Teve ainda por embasamento a consequente construção dos conceitos após as sequências didáticas, através da Sequência Didática Interativa (SDI).

A pesquisa foi realizada com 24 alunos, de uma turma de $2^{\circ}$ ano do Ensino Médio, que se dispuseram voluntariamente após a assinatura dos Termos de Consentimento Livre e Esclarecido (TCLE). A fim de manter o sigilo dos sujeitos da pesquisa, utilizamos nomes populares de plantas da região nordestina brasileira para identificar os participantes. Preferimos nomes de plantas a numerações, para manter também a pessoalidade desses indivíduos e ainda aproximá-los da temática proposta neste trabalho. Em oito encontros de 180 minutos cada, executou-se a sequência didática, com a exposição e discussão do conteúdo "Reino Plantae". 
Inicialmente, foi proposta uma problematização norteadora para os discentes:

Por muitos anos, os fungos e as plantas eram considerados como sendo muito semelhantes. Com o avanço dos estudos, percebeu-se que as plantas deveriam estar alocadas num grupo taxonômico próprio. Para isso, foram listadas diversas características que as tornam distintas. Que características são essas?

Ao longo dos encontros, esse questionamento inicial era retomado, a fim de promover nos estudantes as devidas relações entre os conteúdos vivenciados. Conforme o quadro 1 , onde se lista os conteúdos e suas respectivas abordagens, em cada aula o docente trazia uma exposição dialogada com os recursos didáticos e com os próprios estudantes, que tinham oportunidade de se posicionar para trazer seus questionamentos e considerações.

Quadro 1: Sequência de conteúdos e abordagens

\begin{tabular}{|c|c|c|}
\hline Tema & Recurso didático & Objetivos \\
\hline $\begin{array}{lll}\text { Diversidade } & \text { e } & \text { Histologia } \\
\text { Vegetal } & & \\
\end{array}$ & $\begin{array}{l}\text { Documentário "A vida das } \\
\text { plantas", original de "The secret } \\
\text { of weed", by EBS - South Korea. }\end{array}$ & $\begin{array}{l}\text { - Identificar os principais tipos de } \\
\text { células e como esses tecidos } \\
\text { promovem a estruturação } \\
\text { vegetal. }\end{array}$ \\
\hline Anatomia Vegetal & $\begin{array}{l}\text { Exibição de diversas partes das } \\
\text { plantas, trazidas pelos } \\
\text { estudantes e discussão. }\end{array}$ & $\begin{array}{l}\text { - Distinguir constituição e função } \\
\text { dos órgãos vegetais, bem como } \\
\text { sua diversidade. }\end{array}$ \\
\hline Fisiologia Vegetal & $\begin{array}{l}\text { Elaboração de modelos } \\
\text { didáticos com massa de } \\
\text { modelar e isopor, relacionados } \\
\text { aos tropismos e condução de } \\
\text { seiva. }\end{array}$ & $\begin{array}{l}\text { - Compreender } \\
\text { funcionamento das plantas, } \\
\text { referindo a fotossíntese, } \\
\text { respiração e transpiração. }\end{array}$ \\
\hline Reprodução & 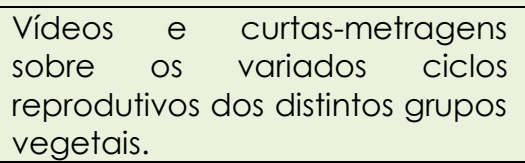 & $\begin{array}{l}\text { - Discernir entre os tipos de } \\
\text { reprodução, bem como entre } \\
\text { gametas, esporos e ciclos. }\end{array}$ \\
\hline Filogenética & $\begin{array}{l}\text { Construção de árvores } \\
\text { filogenéticas dos vegetais, jogos } \\
\text { de perguntas e respostas sobre } \\
\text { evolução das plantas em } \\
\text { relação aos demais reinos. }\end{array}$ & $\begin{array}{l}\text {-Compreender a evolução das } \\
\text { plantas e o parentesco } \\
\text { evolutivo dos principais grupos } \\
\text { (de briófitas às angiospermas) }\end{array}$ \\
\hline
\end{tabular}

Fonte: Os autores. 
Num segundo momento, utilizamos a Sequência Didática Interativa (SDI), onde os estudantes revelaram suas percepções sobre o tema. Segundo Oliveira (2013), a SDI tem como proposta a construção e reconstrução de conceitos sobre diferentes temas dos componentes curriculares através de uma sucessão de atividades para sistematização dos conceitos individuais seguida de uma só definição do tema em estudo. Nessa direção, Silva (2012) aponta que quando a SDI é iniciada entre os participantes, os conhecimentos que estes possuem se apresentam como lógicas convergentes e/ou divergentes que contribuem para um fenômeno organizado, o diálogo.

Em geral, este recurso metodológico é utilizado para investigar concepções prévias dos estudantes (OLIVEIRA, 2011; MOURA, 2012; SILVA; OLIVEIRA, 2016). Neste trabalho, porém, utilizamos a SDI para resgatar a construção do conceito de planta ao longo de um bimestre letivo, a fim de analisar como uma sequência didática contribui para essa construção.

Propomos aqui uma adaptação deste aporte metodológico, a fim de torná-lo congruente com a realidade do contexto da pesquisa. Em se tratando de uma turma de Ensino Médio, onde muitos estudantes se mostram tímidos ou introspectivos para expor suas ideias, não utilizamos a sequência tradicional, com definições individuais, seguidas de grupos com quatro integrantes e concluindo com o grande grupo. Em nosso contexto, inserimos após as definições individuais, uma etapa em duplas, a fim de instigar a interação entre os pares e facilitar a agregação em grupos maiores seguidamente, tendo em vista que a proposta da metodologia interativa, segundo Oliveira (2001), é permitir a participação efetiva de todos os atores sociais envolvidos na pesquisa, eliminando-se ao máximo a subjetividade do pesquisador.

Desse modo, inicialmente, cada estudante foi convidado a escrever, de forma individual, em uma pequena ficha o que entendia por plantas. Em seguida, propomos a divisão do grupo-classe em duplas para a construção de uma nova definição. Na terceira etapa, reuniram-se em grupos de quatro 
integrantes, cada, a fim de que sintetizassem os conceitos construídos por cada participante em mais uma nova definição. Vale ressaltar aqui a importância de que o que cada participante disse sobre o tema seja contemplado na definição final. Por fim, todos os grupos escolheram um representante para a formação de um grande grupo, neste caso com seis integrantes, para sistematização dos conceitos de cada pequeno grupo em uma só definição, de acordo com a figura 1. Surge assim, a definição global, que contempla todas as definições dos pequenos grupos, de forma geral.

Figura 1: Esquema do caminho metodológico adaptado da SDI para esta pesquisa.

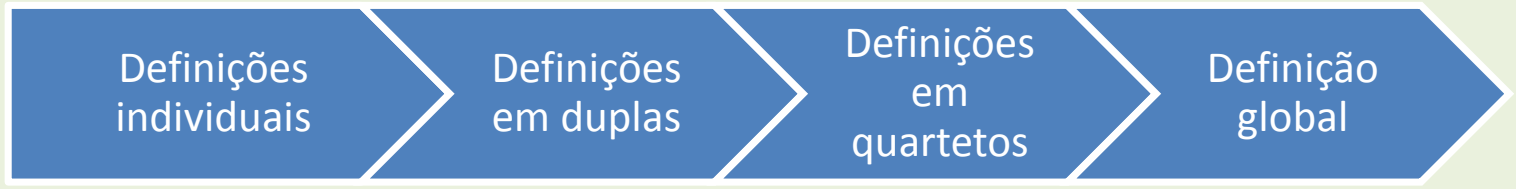

Através desse procedimento é possível, segundo Gondim e Fischer (2009), apreender a língua, o sujeito, a história e a ideologia subjacente. Permitindo assim, compararmos o discurso individual e como ele se mostra em um grupo com interação entre os pares.

Por outro lado, promove-se também entre os estudantes a prática da escrita e da escuta, pois segundo Larrosa (2016), o homem se faz ao se desfazer, a partir do desconhecido que volta a começar. O homem se diz ao se desdizer: no gesto de apagar o que acaba de ser dito, para que a página continue em branco.

Esta prática viabiliza a comunicação e a construção conjunta, cada vez menos instigadas numa sociedade individualista. Compreende-se assim, a relevância da escolha da SDI, pois, de acordo com Moura (2012), a partir da interação dos grupos, novos significados e conhecimentos são reconstruídos a partir dos já existentes. 


\section{RESULTADOS E DISCUSSÃO}

Com relação a primeira parte da pesquisa, que se debruça sobre as definições individuais sobre plantas, foram obtidas respostas dos mais variados tipos. Dentre elas, $62,5 \%$ apresentam uma percepção utilitarista das plantas, servindo aos animais e principalmente ao homem, com remédios, alimentos e até mesmo abrigo.

Cacto: "Um ser vivo muito importante para o homem, onde ele se beneficia muito tanto na forma medicinal, alimentícia e até como temperos."

Umbuzeiro: "Algo muito importante para nós seres humanos, mas também para animais, que dali produz seu alimento e remédios, então devemos preservar as plantas."

Aroeira: "Seres vivos fototróficos, ricos em células e importância gigantesca para os animais e para os seres humanos, produzindo alimentos e $\mathrm{CO}_{2}$ que são elementos muito importantes para sobrevivência, também servem de moradia para animais e vários fins para o homem."

Outro grupo de respostas apresenta definições que utilizam conceitos relacionados à histologia e fisiologia vegetal, bem como aspectos taxonômicos:

Caroá: "Ser multicelular fotossintético que ajuda a restaurar o solo não fértil e na absorção de material orgânico morto."

Xique xique: "Planta é eucarionte, multicelular, muitas das vezes clorofilada, com tecidos diferenciados, sendo subdividas em briófitas, pteridófitas, gimnospermas e angiospermas. Ser de grande importância para a vida na Terra, controla o ciclo da água e o nível de $\mathrm{O}_{2}$."

Juazeiro: "Um ser fotossintetizante, multicelular, que produz seu próprio alimento. Em sua maioria verdes pela presença de cloroplastos em suas folhas".

Uma parte das definições cita também a fotossíntese, mesmo com concepções alternativas:

Mandacaru: "Ser vivo que faz fotossíntese, que tem a função de liberar $\mathrm{H}_{2} \mathrm{O}$ no caso gás oxigênio e absorve $\mathrm{CO}_{2}$, tem seu pigmento verde e com várias ramificações". 
Jurema: "É um ser altamente essencial ao meio ambiente e ao ser humano. Ela é uma grande fornecedora de $\mathrm{O}_{2}$, responsável pelo ciclo da água, fonte nutritiva e entre outras coisas".

Encontramos ainda uma visão holística das plantas participando das teias alimentares, do ciclo hidrológico, de relações mutualísticas, sempre com ressalvas de sua importância para o ecossistema, como pode ser evidenciado nos seguintes trechos: "[...]controla o ciclo da água[...]", "Segue com o mutualismo entre bactérias e fungos." e ainda "Ser que faz muito bem para o nosso planeta e sem ele não viveríamos". Significativa parte das respostas ainda trazem a ideia de plantas como purificadoras do ar, a partir da produção de oxigênio, que de acordo com Brito (2009) se trata de uma crença generalizada: plantas são agentes despolvidores do ar.

Segundo Bonfim et al, (2015) o conhecimento relativo às plantas relatado pelos discentes revela que o professor dispõe de uma ferramenta adicional para trabalhar o conteúdo de Botânica de forma que o aluno seja protagonista da ressignificação dos conceitos. Para isso, o docente deve saber lidar com o conhecimento prévio trazido pelos estudantes e promover novas interações, a fim de contribuir para a elaboração de novos conceitos.

Algumas respostas ainda apresentam as relações evolutivas das plantas, citando seu grau de parentesco ou a diversidade do grupo: "são seres com milhões de anos", ou "Um ser vivo que tem vários mecanismos adaptativos que já foram conseguidos com o passar de milhões de anos.", "classificadas em briófitas, pteridófitas e angiospermas." e ainda "com bastante riqueza em seu reino". Observa-se assim o resgate, nas definições, de temas e/ou conceitos relacionados diretamente aos conteúdos vivenciados durante a sequência didática com suas variadas abordagens. Os estudantes em suas respostas, citam aspectos morfológicos, teciduais, evolutivos, fisiológicos, reprodutivos e até mesmo holísticos, sobre as plantas. Desse modo, concordamos com Oliveira (2013), ao perceber que a SDI promove a construção e reconstrução dos conceitos, a partir de uma sequência de atividades diversas. Os temas ministrados aparecem nas 
respostas - ainda que de forma superficial - revelando a assimilação dos conceitos por parte dos discentes.

No segundo momento, aparecem as definições dadas pelas duplas. Neste grupo de respostas, se mantem a percepção utilitarista, a fotossíntese, a presença de clorofila e a purificação do ar entre os estudantes. Aparecem ainda aspectos celulares e fisiológicos nas definições, como bem ilustram as respostas seguintes:

"Organismo que regula o meio ambiente, que ajuda a tornar o planeta habitável. As plantas têm suas funções, mas, sem elas não haveria vida dependente do oxigênio na terra. Planta é vida que dá origem a outras vidas".

"É um ser vivo que fornece benefícios para a humanidade, animais e planeta; por exemplo fornecendo alimento, medicamentos e repor $\mathrm{O}_{2}$ ".

"É um ser multicelular, eucarioto, autotrófico, grande responsável pela produção de $\mathrm{O}_{2}$, fornecedor de nutrientes para o ciclo da vida".

Estas concepções acima citadas podem ser estudadas à luz da dos pressupostos teóricos do perfil conceitual (AMARAL e MORTIMER, 2001; ELHANI e BIZZO, 2002), onde as ideias primeiras dos estudantes não devem ser descartadas por completo em busca de uma reelaboração total. Ao contrário, o conhecimento prévio mantém o seu lugar cognitivo, de onde o estudante parte, alargando as fronteiras do saber.

No terceiro momento, obtivemos os dados referentes aos grupos, como se mostra no Quadro 2, com as definições propostas pelos quartetos. 
Quadro 2: Definições dos grupos

\begin{tabular}{|c|l|}
\hline Grupo & \multicolumn{1}{c|}{ Resposta } \\
\hline $\mathbf{1}$ & $\begin{array}{l}\text { "É um ser vivo fundamental para a vida, pois ajuda na respiração dos outros } \\
\text { seres vivos produzindo oxigênio através da fotossíntese, sendo aproveitada } \\
\text { na alimentação e na produção de medicamentos." }\end{array}$ \\
\hline $\mathbf{2}$ & $\begin{array}{l}\text { "Ser vivo que trabalha na produção de O2. Cada planta tem uma função } \\
\text { designada. Algumas com mais camadas, com mais células e diversas } \\
\text { funções. Tendo uma relação de fotossíntese com a respiração." }\end{array}$ \\
\hline $\mathbf{3}$ & $\begin{array}{l}\text { "É um organismo vivo que deixa o solo mais fértil, realiza fotossíntese e } \\
\text { absorve matéria do solo. Suas estruturas o auxiliam em crescimento, } \\
\text { desenvolvimento e absorção de nutrientes. " }\end{array}$ \\
\hline $\mathbf{4}$ & $\begin{array}{l}\text { "Planta tem diversas utilidades tanto na natureza e na vida dos seres } \\
\text { humanos, pois além de fazer a fotossíntese e servir de abrigo elas são usadas } \\
\text { para fazer medicamentos e decorações. Aprendemos também que além de } \\
\text { comermos frutos comemos os caules e as folhas. " }\end{array}$ \\
\hline $\mathbf{5}$ & $\begin{array}{l}\text { "Organismo vivo, eucarionte, multicelular, autotrófico, geralmente clorofilado } \\
\text { que realiza fotossíntese, importante para o homem e para o meio por conta } \\
\text { de seus diversos nutrientes, sais minerais nos quais necessitamos para viver." }\end{array}$ \\
\hline $\mathbf{6}$ & $\begin{array}{l}\text { "Tem extrema importância para economia, para controlar o ciclo da água, } \\
\text { para controlar o nível de O2, entre outros. De maneira científica: são seres } \\
\text { eucariontes, multicelulares, com diferenciação de tecidos e geralmente } \\
\text { clorofilados." }\end{array}$ \\
\hline
\end{tabular}

Fonte: Os autores.

Ao acompanhar o avanço das etapas da SDI, percebe-se, de acordo com Silva (2012), que os conceitos elaborados pelos estudantes são mediados pela intervenção de outros colegas, dando prosseguimento ao diálogo e à representação da realidade, em busca da construção de novos conhecimentos. O autor ressalta que este percurso metodológico propõe e promove então, a articulação entre os conhecimentos prévios dos estudantes e o conhecimentos sistematizado pelas discussões.

Por fim, como resultado final da SDI, obtemos o seguinte discurso coletivo, presente na definição global:

"É um ser fotossintetizante, autótrofo, eucarioto e multicelular. É uma fonte de energia, responsável pela produção de $\mathrm{O}_{2}$, tem grande fonte nutritiva. Elas funcionam como medicamento natural. Algumas são grandes e esparsas por conta de seus meristemas, possuem tecido de sustentação, absorção, assimilação, proteção, etc. Fonte de sais minerais, aproveitando 
toda sua estrutura, pode servir como erva medicinal e é um grande participante do ciclo da água".

A definição global traz assim, mais uma vez, aspectos utilitaristas, celulares, teciduais, fisiológicos e holísticos das plantas. Observamos ao longo das respostas um acúmulo das proposições iniciais dos estudantes, que reverberam na construção em grupo.

Quadro 3: Palavras-chaves do discurso global

\begin{tabular}{|c|c|c|c|c|c|}
\hline Aspecto & Celular & Tecidual & Fisiológico & Utilitário & Holístico \\
\hline $\begin{array}{l}\text { Palavras- } \\
\text { chaves }\end{array}$ & $\begin{array}{l}\text { Eucarioto; } \\
\text { Multicelular }\end{array}$ & $\begin{array}{l}\text { Meristemas; } \\
\text { Tecido }\end{array}$ & $\begin{array}{l}\text { Fotossintetizante; } \\
\text { Autotrófo }\end{array}$ & $\begin{array}{l}\text { Erva } \\
\text { medicinal; } \\
\text { Fonte } \\
\text { nutritiva; } \\
\text { Medicamento }\end{array}$ & $\begin{array}{l}\text { Ciclo da } \\
\text { água; }\end{array}$ \\
\hline
\end{tabular}

Fonte: Os autores.

Em outra via, é possível visualizar também quais aspectos de uma planta os estudantes do grande grupo consideraram cruciais para a definição. Com certeza, no diálogo entre os pares, algumas percepções mais individualistas - foram preteridas a fim de englobar falas que alcançassem um espectro maior de concordância. Essa atividade de diálogo que gera aprendizagem é chamada por Larrosa (2016) de logos pedagógico, um logos que resiste em se fixar em dogma, num contínuo jogo entre o dizer e 0 já dito. Para o autor esta atitude dialógica gera aprendizagem por permitir o excesso da atividade de pensar sobre 0 resultado do pensado, a interrupção do dizer monológico e o desvio do curso linear do discurso.

Na definição global, em dois trechos distintos, os estudantes se referem ao caráter medicinal das plantas: "Elas funcionam como medicamento natural." e ainda "[...] pode servir como erva medicinal[...]. Embora saibamos que não é a totalidade das plantas que possui esse caráter terapêutico, para os discentes - face às suas experiências - essa é uma característica marcante. Esta não-linearidade na construção do discurso reflete uma 
construção conjunta, que se distancia do ato "decoreba" e mecânico das salas de aula, frente ao extenso conteúdo de Biologia, aproximando-se de uma ação refletida, dialogada, pensada.

Os termos eucariotos, multicelular e autótrofo por sua vez, sinalizam a construção de novos conceitos que, apareciam em menor proporção nas definições individuais. Aqui, na construção global, estes termos ora distantes, se tornam parte constitutiva do discurso, refletindo mais uma vez, possivelmente, uma bem sucedida realização da SDI.

Uno (2009) afirma que os estudantes utilizam conceitos que já sabem para construir novos conhecimentos, através de diversas habilidades e estratégias, resultantes explícitos da interação entre o conhecimento que herdam da cultura primeira e o conhecimento das experiências sociais. Esses pré-conceitos herdados devem ser lapidados no âmbito escolar que, conforme Libâneo (2004), continua sendo o ambiente de mediação cultural que através dos docentes desenvolve habilidades nos estudantes para aquisição dos conceitos científicos na formação de cidadãos capazes de refletir conscientemente perante problemas enfrentados no cotidiano e de tomar as necessárias decisões racionais.

Um possível caminho para esta mediação, é apontado por Behrens (2013), como uma proposta real, próxima de nossas possibilidades - dados os diversos contextos de ensino e aprendizagem - escolares. A autora indica o envolvimento do estudante em construções coletivas bem sistematizadas, com responsabilidades definidas e produções individuais e de grupo.

É fundamental, como afirmam Salatino e Buckeridge (2016), que os professores superem suas eventuais antipatias por botânica, aproximando mais os estudantes das plantas. Não só os professores, mas ainda, demais componentes da comunidade escolar, cientistas e associações acadêmicas. 


\section{CONSIDERAÇÕES FINAIS}

O ensino de Botânica urge a necessidade de um nova prática pedagógica, não como modelos e receitas prontas. No entanto, cabe aqui apontarmos a contextualização e a problematização nas aulas, como forma de obter ligação entre o conhecimento prévio dos estudantes e os novos conceitos que serão formados.

Com novas pesquisas no ensino de ciências, se encontrarão novos olhares para a realidade escolar - intrinsecamente ligada aos docentes e aos estudantes - apontando uma reformulação na didática, promovendo um processo de ensino e aprendizagem sóbrio, inclusivo, renovador, que permite alargar fronteiras, do conhecimento prévio ao conhecimento científico.

Como afirma Uno (2009), devemos fornecer aos estudantes amplas oportunidades para engajar-se no processo de descoberta nas aulas e ainda aplicar o conhecimento conceitual e científico em suas vidas fora da sala de aula. Caso contrário, nos arriscamos a perder uma futura geração de cidadãos cientificamente alfabetizados.

\section{REFERÊNCIAS}

AMADEU, S. O.; MACIEL, M. D. A dificuldade dos professores de educação básica em implantar o ensino prático de Botânica. Revista de Produção Discente em Educ. Matemática, v.3, n.2, 2014, p.225 - 235.

AMARAL, E. M. R.; MORTIMER, E. F. Uma proposta de perfil conceitual para o conceito de calor. Revista Brasileira de Pesquisa em Educação em Ciências, v. 1, n. 3, p. $1-14,2001$.

ARAÚJO, J. N.; SILVA, M. F. V. Aprendizagem significativa de Botânica em ambientes naturais. Revista Areté, v.8, n.15, 2015, p. 100 - 108.

AUSUBEL, D. P.; NOVAK, J. D.; HANESIAN, H. Educational psychology: a cognitive view. Holt, Rinehardt \& Winston: Nova York, 1978.

BARMAN, C. R.; STEIN, M.; MCNAIR, S.; BARMAN, N. S. Students' Ideas About Plants \& Plant Growth. The American Biology Teacher, v. 68, n. 2, 2006, p. 7379. 
BAUER M. V.; GASKELL, G.; ALLUM, N. C. Quantidade, qualidade e interesse do conhecimento: evitando confusões. In: BAUER M. V.; GASKELL, G. (Orgs.). Pesquisa qualitativa com texto, imagem e som - um manual prático. Petropólis: Vozes, 2002.

BEHRENS, M. A. O paradigma emergente e a prática pedagógica. Petrópolis: Vozes, 2013.

BELL, B. F. What is a plant: Some children's ideas. New Zealand Science Teacher, v. 31, 1981, p. 10-14.

BITENCOURT, I. M.; MACEDO, G. E. L.; SOUZA, M. L.; SANTOS, M. C.; SOUSA, G. P.; OLIVEIRA, D. B. G. As plantas na percepção de estudantes do ensino fundamental no município de Jequié-BA, In: VII ENPEC- ENCONTRO NACIONAL DE PESQUISA EM EDUCAÇÃO EM CIÊNCIAS. Anais. Campinas, 2011.

BLOOR, D. Conhecimento e imaginário social. São Paulo: Editora UNESP, 2009. BOCKI, A. C.; LEONÊS, A. S.; PEREIRA, S. G. M.; RAZUCK, R. C. S. R. As concepções dos alunos do Ensino Médio sobre Botânica. In: VIII Encontro Nacional de Pesquisa. Anais do Encontro. Campinas: ABRAPEC, 2011.

BONFIM, L. R. M.; TAVARES-MARTINS, A. C. C.; PALHETA, I. C.; JUNIOR, A. S. M. O Ensino de Botânica em escolas públicas e particulares no município de Barcarena, Pará, Brasil. Areté: Revista Amazônica de Ensino de Ciências, v. 8 , n. 17, 2015, p. $167-176$.

BRASIL. Ciências da Natureza, Matemática e suas tecnologias / Secretaria de Educação Básica. Brasília: Ministério da Educação. Secretaria de Educação Básica, 2008. 135 p. (Orientações curriculares para o ensino médio: Volume 2).

BRASIL. Parâmetros curriculares nacionais: Ciências naturais. Secretaria de Educação Fundamental. Brasília: MEC/SEF, 1998.137 p.

BRITO, S. D. A botânica no ensino médio: uma experiência pedagógica sob uma perspectiva construtivista. UESB/ Vitoria da Conquista, 2009 (monografia de graduação).

CECCANTINI, G. Os tecidos vegetais têm três dimensões. Revista Brasileira de Botânica. São Paulo, v. 29, n. 2, 2006, p. 335 - 337.

EL-HANI, Cl. N.; BIZZO, N. M. V. Formas de construtivismo: teoria da mudança conceitual e construtivismo contextual. Ensaio Pesquisa em Educação em Ciências, v. 4, n. 1, p. $1-25,2002$.

HERSHEY, D. R. Avoid misconceptions when teaching about plants [online]. Website. Disponível em: <http://www.actionbioscience.org/education/hershey.html >. 2004. Acesso em Maio 2016. 
HERSHEY, D. R. More misconceptions to avoid when teaching about plants [online]. Website. Disponível em: <http://www.actionbioscience.org/education/hershey3.html > 2005. Acesso em Maio de 2016.

KELLER, E. F. The century beyond the gene. Journal of Biosciences, v. 30, n. 1, P. $101-118,2005$.

LARROSA, J. Pedagogia profana: danças, piruetas e mascaradas. Belo Horizonte: Autêntica, 2016.

LARROSA, J. Tremores: escritos sobre a experiência. Belo Horizonte: Autêntica, 2016.

MENEZES, Luan C.; SOUZA, Vênia Camelo; NICOMEDES, Mário Pereira; QUIRINO, Max Rocha; SANTOS, Betânia Cosme Araújo dos. Iniciativas para o aprendizado de Botânica no Ensino Médio. In: XI ENCONTRO DE INICIAÇÃO À DOCÊNCIA, Anais, UFPB- PRG, 2008.

MORAIS, R. Evoluções e revoluções da Ciência atual. Campinas: Alínea, 2007. MORALES, C. J. S. O processo de ensino e aprendizagem no Ensino de Ciências. Revista Areté, v.7, n.14, 2014, p. 01-15.

MORTIMER, E. F.; EL-HANI, C. N. Um visão sócio-interacionista e situada dos conceitos e a internalização em Vygotsky. In: IX Encontro Nacional de Pesquisa em Educação em Ciências. Atas do IX ENPEC, Águas de Lindoia, SP. 2013.

MOURA, R. M. Professor reflexivo no ensino de ciências utilizando a sequência didática interativa. In: VI Colóquio Internacional Educação e Contemporaneidade. Anais do Educonse, São Cristovão, Sergipe, 2012.

OLIVEIRA, M. M. Círculo hermenêutico-dialético como sequência didática interativa, Interfaces Brasil / Canadá, v. 11, n. 1, p. 235 - 251, 2011.

OLIVEIRA, M. M. Metodologia Interativa: um processo hermenêutico dialético. Revista Interfaces Brasil/Canadá. Porto Alegre, V1, N. 1, p. 67-78, 2001.

SALATINO, A.; BUCKERIDGE, M. Mas de que te serve saber botânica? Estudos avançados, v. 30, n. 87, p. 177 - 196, 2016.

SANTOS, S. Para geneticistas e educadores: o conhecimento cotidiano sobre herança biológica. São Paulo: Annablume; FAPESP; SBG, 2005.

SILVA, J. P. G. Sequência Didática Interativa: uma proposta para o trabalho docente. In: OLIVEIRA, M. M. (Org.). Formação de professores: estratégias inovadoras no ensino de Ciências e Matemática. Recife: Editora Universitária da UFRPE, 2012, p. $172-193$.

SILVA, L. M.; CAVALLET, V. J.; ALQUINI, Y. O professor, o aluno e o conteúdo no ensino de botânica. Revista Educação. Santa Maria - RS, v. 31, n. 1, 2006, p. 67-80. 
SILVA, J. N.; GHILARD-LOPES, N. P. Botânica no Ensino Fundamental: diagnósticos de dificuldades no ensino e da percepção e representação da biodiversidade vegetal por estudantes. Revista Electrónica de Enseñanza de las Ciencias, v. 13, n. 2, 2014, p. $115-136$.

SILVA, S. C. G. M.; OLIVEIRA, M. M. Sequência didática interativa trabalhada como proposta CTS com a temática aquecimento global para a Educação Básica, Revista Eletrônica do Mestrado em Educação Ambiental, v. 33, n. 1, p. $345-364,2016$.

SOUZA, S. C.; ALMEIDA, M. J. P. M. A fotossíntese no Ensino Fundamental: compreendendo as interpretações dos alunos. Ciência e Educação, v. 8, n. 1, p $97-111.2002$.

TOWATA, N.; URSI, S.; SANTOS, D. Y. A. C. Análise da percepção de licenciados sobre o ensino de botânica na educação básica. Revista da SBEnBio, n. 03, 2010, p.1603 - 1612.

UNO, G. E. Botanical literacy: What and how should students learn about plants? American Journal of Botany, v. 96, 2009, p. 1753-1759.

WANDERSEE, J. H., SCHUSSLER, E. E. Preventing plant blindness. American Biology Teacher, v. 61, 1999, p. $84-86$.

Recebido em: Março de 2017 Aceito em: Abril de 2017 